\title{
The Influence of Blending Different Molecular Weights of Cellulose Acetate Butyrate for $\mathrm{CO}_{2} / \mathrm{N}_{2}$ Separation
}

\author{
Dick Shion Chong, ${ }^{1}$ Zeinab Abbas Jawad, ${ }^{1 *}$ Peng Chee Tan ${ }^{2}$ \\ and Mayyadah Shanan Abed Al-Fatlawi ${ }^{3}$ \\ ${ }^{1}$ School of Engineering and Science, Department of Chemical Engineering, \\ Curtin University Malaysia, CDT 250, Miri 98009, Sarawak, Malaysia \\ ${ }^{2}$ School of Energy and Chemical Engineering, Xiamen University Malaysia, \\ Jalan Sunsuria, Bandar Sunsuria, 43900 Sepang, Selangor, Malaysia \\ ${ }^{3}$ Department of Materials Engineering, University of Technology, Baghdad, Iraq \\ *Corresponding author: zeinab.aj@curtin.edu.my
}

Published online: 25 August 2020

To cite this article: Chong, D. S. et al. (2020). The influence of blending different molecular weights of cellulose acetate butyrate for $\mathrm{CO}_{2} / \mathrm{N}_{2}$ separation. J. Phys. Sci., 31(2), 91-112. https://doi.org/10.21315/jps2020.31.2.7

To link to this article: https://doi.org/10.21315/jps2020.31.2.7

\begin{abstract}
Public awareness of the environment and legislation has promoted intensive studies on the reduction of greenhouse gases (GHGs) emission. One of the promising breakthroughs discovered was the polymer blend membrane that demonstrated significant carbon dioxide $\left(\mathrm{CO}_{2}\right)$ /nitrogen $\left(\mathrm{N}_{2}\right)$ separation performance. Instead of other polymers, cellulose acetate butyrate (CAB) polymer was chosen due to its high $\mathrm{CO}_{2}$ sorption ability. This membrane was prepared by optimising the ratios of the $C A B$ molecular weights (Mn) of 12000, 70000 and 30000 to enhance the $\mathrm{CO}_{2} / \mathrm{N}_{2}$ separation. The single gas permeation test results showed that the $\mathrm{CO}_{2} / \mathrm{N}_{2}$ separation performance had increased from $0.7396 \pm 0.0396$ (M3) to $1.8986 \pm 0.0195$ (M6) due to the presence of the hydroxyl $(\mathrm{OH})$ group in the membrane. In this study, the newly fabricated polymer blend membrane demonstrated an improvement in the $\mathrm{CO}_{2} / \mathrm{N}_{2}$ separation performance. Therefore, this membrane qualifies to be applied in the industry.
\end{abstract}

Keywords: Gas separation, polymer blending, solvent exchange drying, polymer molecular weight, cellulose acetate butyrate membrane 


\section{INTRODUCTION}

The effects of global warming caused by the emission of greenhouse gases (GHGs) have been categorised as one of the most important issues since the Industrial Revolution. ${ }^{1}$ It is widely known that the application of alternative energy sources such as renewable energy and nuclear power is an option for reducing GHGs. However, until sufficient research studies prove that these methods are able to generate significant amount of energy, conventional combustion of fossil fuels is likely to continue. ${ }^{2}$ In order to reduce the global warming effects, it is necessary to perform carbon dioxide $\left(\mathrm{CO}_{2}\right)$ separation from flue gas since $\mathrm{CO}_{2}$ dominates $77 \%$ of the total emission of GHGs. ${ }^{3}$

In recent years, membrane technology has drawn much attention because of high performance and high selectivity. ${ }^{4}$ The technology inherits numerous benefits like low energy, low capital costs, environmental friendly materials and modular designs that allow further expansion effortlessly. ${ }^{5}$ One of the materials utilised is cellulose acetate butyrate (CAB). ${ }^{6}$ It has been tested and proven to be an excellent material for $\mathrm{CO}_{2}$ separation because of its high tolerance to chemicals. ${ }^{7}$ Moreover, it is easy to modify its structure for high selectivity characteristics. ${ }^{8}$ In addition, Shanbhag et al. reported that the $\mathrm{CAB}$ membrane surpassed the results when compared to the standard CA membrane for membrane stability and drying time requirements. ${ }^{9}$

However, one of the most important limitations of the polymeric membrane is the challenge in achieving high permeability and high selectivity at the same time due to the morphology of the fabricated membrane. ${ }^{10}$ Therefore, it has become relatively important to control its morphology and one of the methods employed is by controlling the polymer molecular weight $(\mathrm{Mn})$ when preparing the casting solution. ${ }^{11}$ According to Kee and Idris, the pore diameter, the effective surface porosity and permeability of the membrane exhibits an equal increment when the $\mathrm{Mn}$ of the polymer in the casting solution increases. ${ }^{12}$ In addition, when a higher Mn polymer is present in the casting solution, it promotes a lower diffusion rate, which encourages the establishment of a thinner membrane with lower resistance to gas permeation. ${ }^{13}$ A major drawback of a polymer blend membrane is the difficulty in establishing an optimum ratio when its hydrophilic characteristic is modified..$^{14}$

Based on this, the aim of this study is to fabricate a polymer blend membrane by optimising the polymer's Mn. Over the decades, numerous studies and researches have been undertaken to demonstrate the advantages of the $\mathrm{CAB}$ membrane in the gas separation field as well as separation of $\mathrm{CO}_{2}$ from flue gas due to its high emission since the industrial revolution. ${ }^{15}$ Nevertheless, no studies have been conducted to evaluate the effect of blending different ratios of the $\mathrm{CAB}$ polymer 
with Mn of 12000, 70000 and 30000 with the polar acetyl group of 16-19 wt\%, $12-15 \mathrm{wt} \%$ and $12-15 \mathrm{wt} \%$, respectively, on the separation of the non-polar $\mathrm{CO}_{2} / \mathrm{N}_{2}$. It is believed that this work will contribute significantly towards the environment with its high permeation rate, high selectivity, energy efficient and low-cost characteristics.

\section{EXPERIMENTAL}

\subsection{Materials}

CAB of different Mn of 12000, 70000 and 30000 was acquired from SigmaAldrich (Malaysia). The solvent chloroforms ( $\geq 99.7 \%)$ of 2-isopropyl alcohol and n-hexane were purchased from Merck (Malaysia).

\subsection{Fabrication of CAB Membrane}

The $\mathrm{CAB}$ membrane (M1) was fabricated by preparing the casting solution from $4 \mathrm{wt} \%$ of the CAB polymer of different $\mathrm{Mn}$ of 12000 and 70000 at a ratio of $1: 2$ and $96 \%$ of chloroform. The solution was then stirred for $24 \mathrm{~h}$. After the stirring process, the mixture was sonicated for $20 \mathrm{~min}$ to remove any bubble present in the solution in order to develop a neat membrane with smooth surface. ${ }^{16}$ The methodology continued with the membrane casting process by controlling the casting thickness at $250 \mu \mathrm{m}$ with the assistance of a casting machine. ${ }^{17}$ Next, solvent evaporation was performed on the membrane for 5 min under room temperature conditions. Subsequently, the cast membrane was immersed in distilled water at room temperature for $24 \mathrm{~h} .{ }^{18}$ The goal was to eliminate all the residual solvent. With regards to the membrane drying process, the solvent exchange drying method was applied by using 2-isopropyl alcohol as the first solvent for $30 \mathrm{~min}$ followed by $\mathrm{n}$-hexane as the second solvent for $60 \mathrm{~min}$. Lastly, the fabricated membrane was left to dry for $24 \mathrm{~h}$ by evaporation under room temperature to remove any volatile liquid. ${ }^{19}$

\subsection{Effect of Polymer Molecular Weight}

In this research study, the casting solution was prepared by using different ratios for Mn 12000 and 70000 and thus, obtaining the best solvent exchange time. This is tabulated in Table 1. 


\subsection{Effect of Low Mn (30000) Polymer Blend}

The polymer of Mn 30000 was added to the polymer matrix M3 of Mn 12000 and 70000 at a ratio of $1: 2$, as tabulated in Table 1.

Table 1. The composition prepared for membrane fabrication with various polymer concentration.

\begin{tabular}{|c|c|c|c|c|c|c|c|c|}
\hline \multirow{2}{*}{$\begin{array}{l}\text { Membrane } \\
\text { samples }\end{array}$} & \multicolumn{3}{|c|}{$\begin{array}{c}\mathrm{CAB}(\mathrm{wt} \%) \\
(\mathrm{Mn})\end{array}$} & \multirow{2}{*}{$\begin{array}{l}\text { Chloroform } \\
\text { solvent } \\
\text { concentration } \\
\quad(w t \%)\end{array}$} & \multirow{2}{*}{$\begin{array}{l}\text { 2-isopropyl } \\
\text { alcohol } \\
\text { exchange } \\
\text { time } \\
\text { (min) }\end{array}$} & \multirow{2}{*}{$\begin{array}{l}\text { n-hexane } \\
\text { exchange } \\
\text { time } \\
\text { (min) }\end{array}$} & \multirow{2}{*}{$\begin{array}{l}\text { Membrane } \\
\text { casting } \\
\text { thickness } \\
(\mathrm{mm})\end{array}$} & \multirow{2}{*}{$\begin{array}{l}\text { Evaporation } \\
\text { time } \\
\text { (min) }\end{array}$} \\
\hline & 12000 & 70000 & 30000 & & & & & \\
\hline M1 & 2 & 1 & 0 & 96 & 60 & 60 & 250 & 4 \\
\hline M2 & 1 & 1 & 0 & 96 & 60 & 60 & 250 & 4 \\
\hline M3 & 1 & 2 & 0 & 96 & 60 & 60 & 250 & 4 \\
\hline M4 & 1 & 3 & 0 & 96 & 60 & 60 & 250 & 4 \\
\hline M5 & 1 & 2 & 1 & 96 & 60 & 60 & 250 & 4 \\
\hline M6 & 1 & 2 & 2 & 96 & 60 & 60 & 250 & 4 \\
\hline
\end{tabular}

\subsection{Gas Permeation Test}

The gas permeation test of the membrane was carried out with purified $\mathrm{CO}_{2}$ and $\mathrm{N}_{2}$ gases at room temperature conditions. The flow rate of the feed $\left(\mathrm{CO}_{2}\right.$ or $\left.\mathrm{N}_{2}\right)$ was controlled in order to release at a rate of $100 \mathrm{ml} \mathrm{min}{ }^{-1}$ from a compressed gas cylinder with the aid of a mass flow controller (Aalborg AFC 26, United States). At the same time, the controller was linked to a two-channel digital set point/ readout unit device (Aalborg 0-200 $\mathrm{ml} \mathrm{min}^{-1}$, United States). The appointed gas was thereafter injected into the stainless-steel membrane cell with pressure ranging from 1 bar to 3 bars.

To ensure that the results were precise and accurate, several steps were taken during preparation and membrane testing. This included cutting the membrane into the shape of a disc and subsequently, placing it on top of the membrane cell and covering it tightly. In addition, leak detection analysis was carried out to ensure that no circumstance of leakage occurred during the test. The procedure of measuring the flow rate of permeation and retentate was conducted by the assistance of a soap bubble flow meter that measures each volume displacement individually. Figure 1 shows the schematic diagram of an experimental rig set-up. 


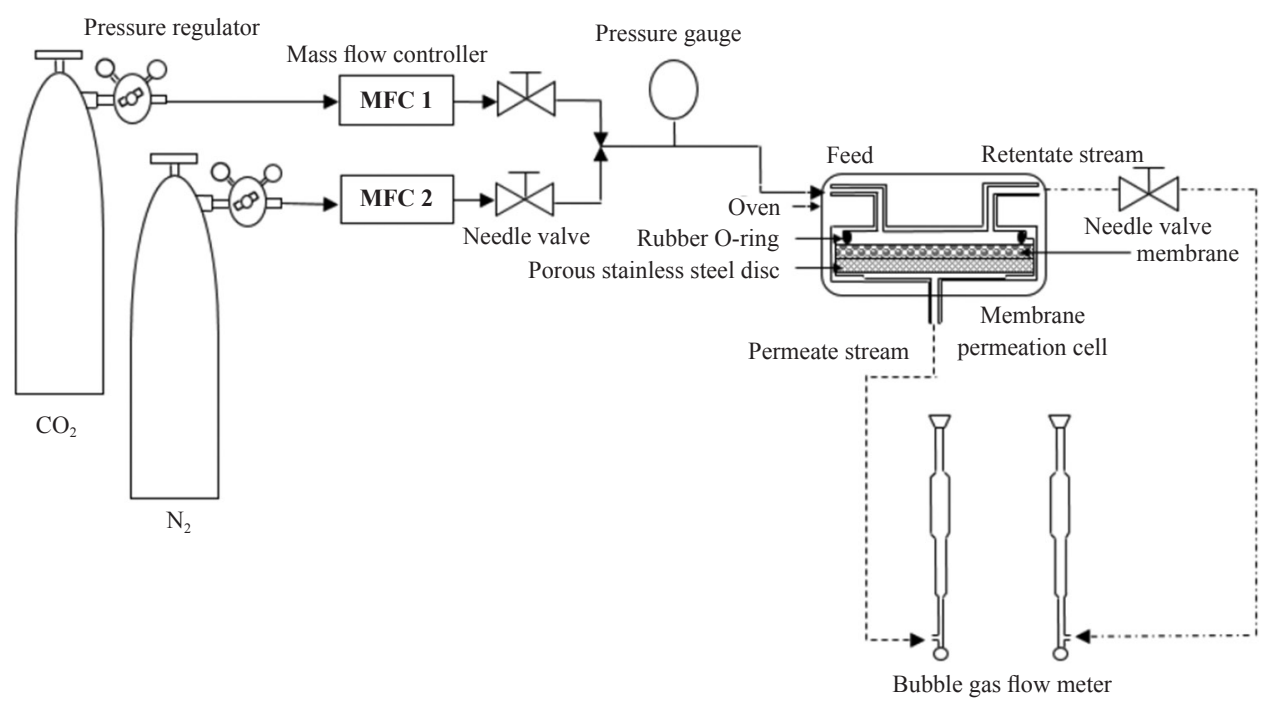

Figure 1: Schematic diagram of the experiment test rig.

The performance of gas separation in terms of gas permeability and selectivity were determined by the application of various dedicated formulas as shown in the subsequent discussion.

The membrane presence $(P / l)$ expressed in GPU was determined by applying Equation 1 below into the calculation. ${ }^{20}$

$$
\frac{P}{l}=\frac{Q}{A \Delta p}
$$

where:

$l=$ The membrane thickness $(\mathrm{cm})$

$A=$ Effective membrane area $\left(\mathrm{cm}^{2}\right)$

$Q=$ The volumetric flow rate at standard condition $\left(\mathrm{cm}^{3} / \mathrm{s}\right)$

$\Delta p=$ The pressure drop across the membrane $(\mathrm{cmHg})$

$1 \mathrm{GPU}=\left[1 \times 10^{-6}\left(\mathrm{~cm}^{3}(\mathrm{STP})\right) /\left(\mathrm{cm}^{2} \mathrm{scmHg}\right)\right]$

Secondly, the calculation of the ratio of permeability for $\mathrm{CO}_{2} / \mathrm{N}_{2}$ was obtained by the application of Equation 2. ${ }^{21}$

$$
\alpha_{\mathrm{CO}_{2} / N_{2}}=\frac{P_{\mathrm{CO}_{2}}}{l_{N_{2}}}=\frac{(P / l)_{\mathrm{CO}_{2}}}{(P / l)_{N_{2}}}
$$




\subsection{Membrane Characterisation}

\subsubsection{ATR-FTIR}

The Attenuated Total Reflectance Fourier Transform Infrared Spectroscopy (ATR-FTIR) was utilised in this study with the aid of the NicoletIS10 (United States) spectrometer having specifications that ranged from $400 \mathrm{~cm}^{-1}$ to $4000 \mathrm{~cm}^{-1}$ across the diamond crystal. The information on background room condition was recorded in advance before collecting the wavelengths of the samples. The process was repeated three times to obtain the average for each sample.

\subsubsection{Membrane Contact Angle}

To obtain the wettability of each membrane sample, the Rame-Hart Model 3000 Advanced Goniometer was utilised in this study. The recorded angles were employed to analyse the membrane properties pertaining to liquid interaction and repulsion forces among its interfacial properties. Ten measurements were obtained from each sample to ensure preciseness of data.

\subsubsection{Scanning Electron Microscopy}

The scanning electron microscope (SEM, Hitachi TM30000, Tokyo, Japan) was used to obtain the morphology of the $\mathrm{CAB}$ membrane. At the beginning of the process, the $\mathrm{CAB}$ membrane specimen was fractured into smaller pieces followed by freezing at a temperature of $-80^{\circ} \mathrm{C}$ in the cryogenic freezer for $24 \mathrm{~h}$. This was to ensure that the consistency and clean crack of the membrane could be achieved. This process was continued by coating the cracked specimen with platinum in order to generate high contrast images. The minimum number of samples required to produce genuine consistent results was decided at five.

\section{RESULTS AND DISCUSSION}

\subsection{Effect of CAB Molecular Weight}

According to Chakarabarty et al., the morphology of a membrane is highly dependent on the Mn available in the casting solution due to variation in the diffusion rate that affects the membrane thickness. ${ }^{11}$ Therefore, it is relatively important to obtain the optimum ratio of different $\mathrm{Mn}$ of the $\mathrm{CAB}$ polymer in order to fabricate a high $\mathrm{CO}_{2} / \mathrm{N}_{2}$ permeance and selectivity membrane. Thus, the $\mathrm{CAB}$ of Mn 12000 was first optimised, followed by optimisation of the CAB of Mn 70000 with solvent exchange time of $60 \mathrm{~min}$ for 2-isopropyl and $60 \mathrm{~min}$ for $\mathrm{n}$-hexane. 


\subsubsection{Membrane characterisation}

Both the surface and cross-sectional morphologies of the fabricated $\mathrm{CAB}$ membrane of Mn 12000 and 70000 at ratios of 2:1 (M1), 1:1 (M2), 1:2 (M3) and 1:3 (M4) are demonstrated in Figure 2. Based on Figures 2(a, c, e), the surface structure of the membrane was rough when the Mn of the $\mathrm{CAB}$ was at 12000 but smooth and defect-free when the $\mathrm{Mn}$ of the $\mathrm{CAB}$ was higher, i.e., at 70000. The rough surfaces formed on M1 and M2 were due to the increase in the hydrophobicity of the membranes, as displayed in Figure 3. The hydrophobic membrane surface reduces the ability of hydrogen to bond to form water, which affects the surface morphology. Based on Figure 3, the contact angle increased from $68.0^{\circ}(\mathrm{M} 2)$ to $69.2^{\circ}$ (M1) when the ratio of Mn 12000 was increased from 1 to 2.

On the other hand, the cross-sectional morphology of the membranes was exhibited in Figures 2(b, d, $f$ and $h)$. As indicated in Figures 2(b and d), the membrane thickness increased from $21.75 \pm 0.0216 \mu \mathrm{m}$ (M2) to $31.49 \pm 0.0542 \mu \mathrm{m}$ (M1) when the ratio of Mn 12000 increased from 1 (M2) to 2 (M1) in the casting solution. This was because the membrane cast with the lower Mn of 12000 had a low propensity of shrinking. ${ }^{12}$ However, the membrane displayed a significant reduction in thickness from $31.49 \pm 0.0542 \mu \mathrm{m}$ (M1), $21.75 \pm 0.0216 \mu \mathrm{m}$ (M2) to $9.80 \pm 0.0399 \mu \mathrm{m}(\mathrm{M} 3)$ when the ratio of the higher Mn of 70000 was increased from 1 (M2) to 2 (M3). The higher Mn of 70000 had a lower diffusion rate as compared to the lower $\mathrm{Mn}$ of 12000 . Therefore, when the cast membrane was in contact with water, the lower Mn of 12000 with higher diffusion rate flowed out from the matrix rapidly causing the higher Mn of 70000 to aggregate. ${ }^{13}$ As a result, a thinner membrane was formed, shown in Figure 2(f). Additionally, the higher Mn of 70000 (M4) had the propensity of shrinking during fabrication due to its higher compact structure. ${ }^{12}$ Thus, M4 had a thickness of $13.39 \pm$ $0.2098 \mu \mathrm{m}$.

\subsubsection{Separation performance of the membranes}

\subsubsection{Single gas permeation test of $\mathrm{CO}_{2}$}

The fabricated membranes M1, M2, M3 and M4 were tested using the single gas permeation test of $\mathrm{CO}_{2}$. Based on Figure 4, when the ratio of the lower $\mathrm{Mn}$ of $\mathrm{CAB}$ at 12000 increased from 1 (M2) to 2 (M1), the $\mathrm{CO}_{2}$ permeance of the membranes decreased significantly from $29.81 \pm 1.3203$ GPU (M2) to $17.32 \pm 1.1039 \mathrm{GPU}(\mathrm{M} 1)$. However, the thickness increased from 21.75 $\pm 0.0216 \mu \mathrm{m}(\mathrm{M} 2)$ to $31.49 \pm 0.0542 \mu \mathrm{m}$ (M1). This is shown in Figure 2. 

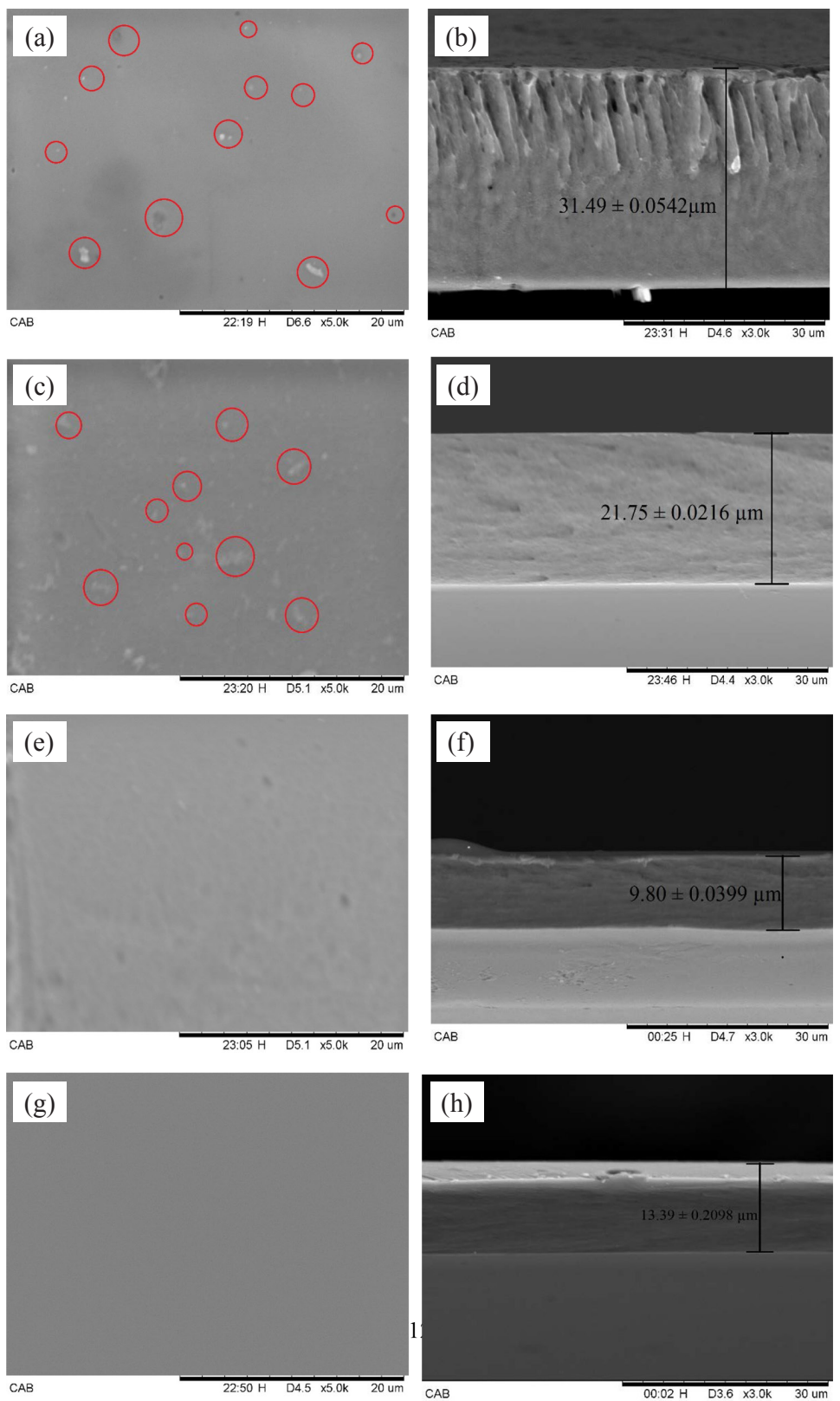

Figure 2: $\quad$ SEM images of $\mathrm{CAB}$ membrane surface and cross sectional structure fabricated from various ratio of CAB of Mn 12000 and 70000; (a, b) 2:1 (M1), (c, d) 1:1 (M2), (e, f) 1:2 (M3) and (g, h) 1:3 (M4) with the $250 \mu \mathrm{m}$ casting thickness, $5 \mathrm{~min}$ solvent evaporation time, $4 \mathrm{wt} \%$ polymer concentration and $60 \mathrm{~min}$ 2-isopropyl alcohol exchange drying time, followed by $60 \mathrm{~min} n$-hexane drying time. 
On the other hand, when the ratio of the higher $\mathrm{Mn}$ of $\mathrm{CAB}$ at 70000 increased from $1(\mathrm{M} 2)$ to $2(\mathrm{M} 3)$ the $\mathrm{CO}_{2}$ permeance increased dramatically from $29.81 \pm$ 1.3203 GPU (M2) to $61.04 \pm 1.0288 \mathrm{GPU}$. The high permeance of $\mathrm{CO}_{2}$ for M3 was due to the higher surface hydrophilicity. This is demonstrated in Figure 3. Based on this figure, when the Mn of 70000 was increased to the ratio of 2 (M3), a more hydrophilic membrane was formed where M3 displayed the lowest contact angle with a value of $67.8^{\circ}$ when compared to M2 and M1, which had higher contact angles of $68.0^{\circ}$ and $69.2^{\circ}$, respectively. The reason for the reduction in the value of the contact angle when the ratio of the $\mathrm{CAB}$ of Mn 70000 increased was due to the extra hydroxyl $(-\mathrm{OH})$ present in the polymer. This is shown in the higher stretching vibrations of the FTIR in Figure 5 where the hydrophilicity of the membrane surface is enhanced. ${ }^{22}$ According to a study, the $-\mathrm{OH}$ functional group increases the hydrophilicity of the membrane surface. ${ }^{12}$ Thus, the $\mathrm{CO}_{2}$ permeance of M3 increased. The increase was attributed mainly to the availability of the polar functional groups $(-\mathrm{OH})$, which have the potential to react with the non-polar $\mathrm{CO}_{2}$ gas. ${ }^{23}$ On the contrary, when the ratio of the $\mathrm{CAB}$ of Mn 70000 was increased to 3 (M4), the $\mathrm{CO}_{2}$ permeance decreased dramatically to 19.15 \pm 1.6949 GPU resulting in the increase of the membrane thickness from $9.80 \pm$ $0.0399 \mu \mathrm{m}$ (M3) to $13.39 \pm 0.2098 \mu \mathrm{m}$ (M4), as shown in Figure 2. This is because the permeance of a membrane is inversely proportional to its cross-sectional thickness. $^{24}$

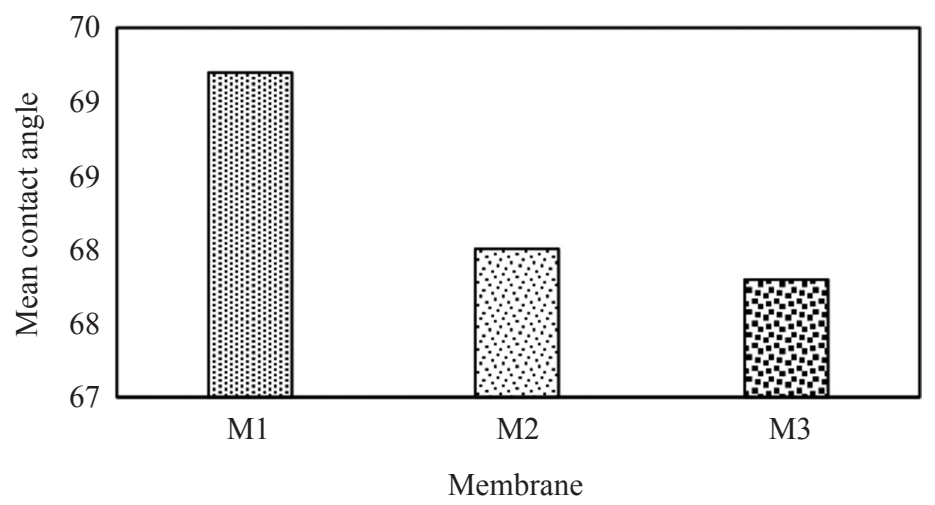

Figure 3: Contact angle of $\mathrm{CAB}$ membrane fabricated from various ratios of $\mathrm{CAB}$ of $\mathrm{Mn}$ 12000 and 70000, M1 (2:1), M2 (1:1) and M3 (1:2), with the $250 \mathrm{~mm}$ casting thickness, $5 \mathrm{~min}$ solvent evaporation time, $4 \mathrm{wt} \%$ polymer concentration and $60 \mathrm{~min}$ 2-isopropyl alcohol exchange drying time, followed by $60 \mathrm{~min}$ n-hexane drying time. 


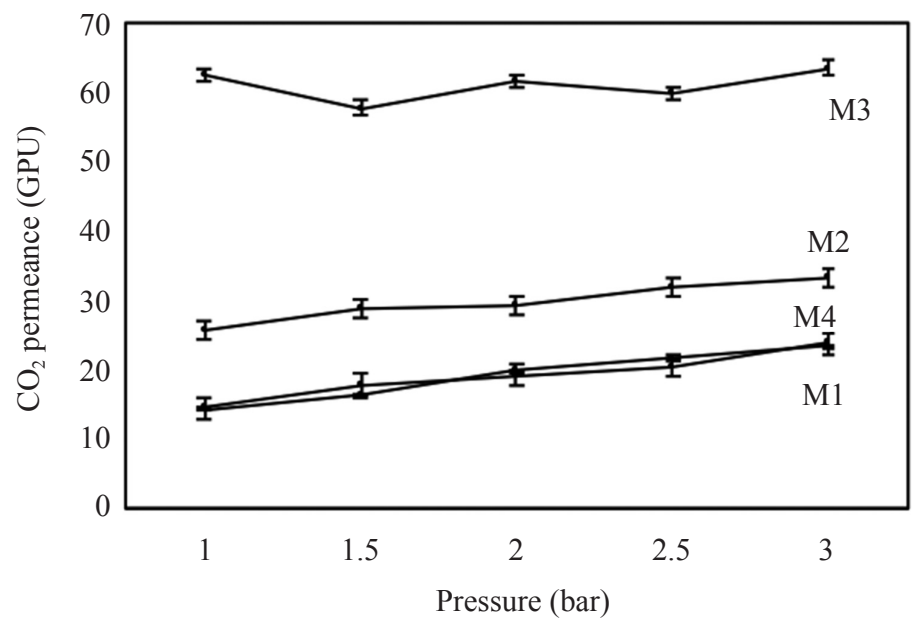

Figure 4: $\mathrm{CO}_{2}$ permeance of $\mathrm{CAB}$ membrane fabricated from various ratio of $\mathrm{CAB}$ of Mn 12000 and 70000, M1 (2:1), M2(1:1), M3 (1:2) and M4 (1:3) with the $250 \mu \mathrm{m}$ casting thickness, $5 \mathrm{~min}$ solvent evaporation time, $4 \mathrm{wt} \%$ polymer concentration and $60 \mathrm{~min}$ 2-isopropyl alcohol exchange drying time, followed by $60 \mathrm{~min} n$-hexane drying time.

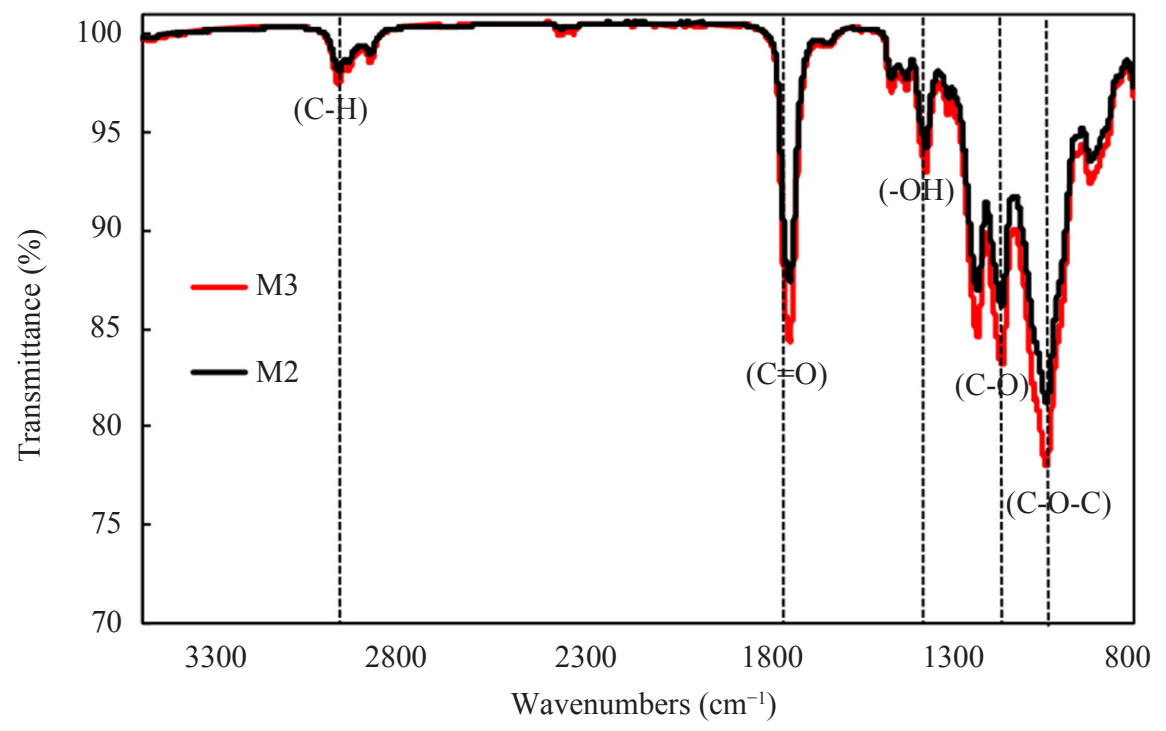

Figure 5: ATR-FTIR spectra of selected CAB membrane M3 (1:2) and M2 (1:1) fabricated from $\mathrm{CAB}$ of $\mathrm{Mn}$ of 12000 and 70000 , with the $250 \mu \mathrm{m}$ casting thickness, 5 min solvent evaporation time, $4 \mathrm{wt} \%$ polymer concentration and $60 \mathrm{~min} 2$-isopropyl alcohol exchange drying time, followed by $60 \mathrm{~min} n$-hexane drying time. 


\subsubsection{Single gas permeation test of $N_{2}$}

Similarly, the membranes were evaluated using the single gas permeation test of $\mathrm{N}_{2}$. Based on Figure 6, the $\mathrm{N}_{2}$ permeance decreased from $38.36 \pm 0.6954$ GPU to $23.99 \pm 0.7500 \mathrm{GPU}$ when the ratio of the Mn of 12000 increased from 1 (M2) to 2 (M1) causing the membrane thickness to increase from $21.75 \pm 0.0216 \mu \mathrm{m}$ (M2) to $31.49 \pm 0.0542 \mu \mathrm{m}(\mathrm{M} 1)$. This is presented in Figure 2 .

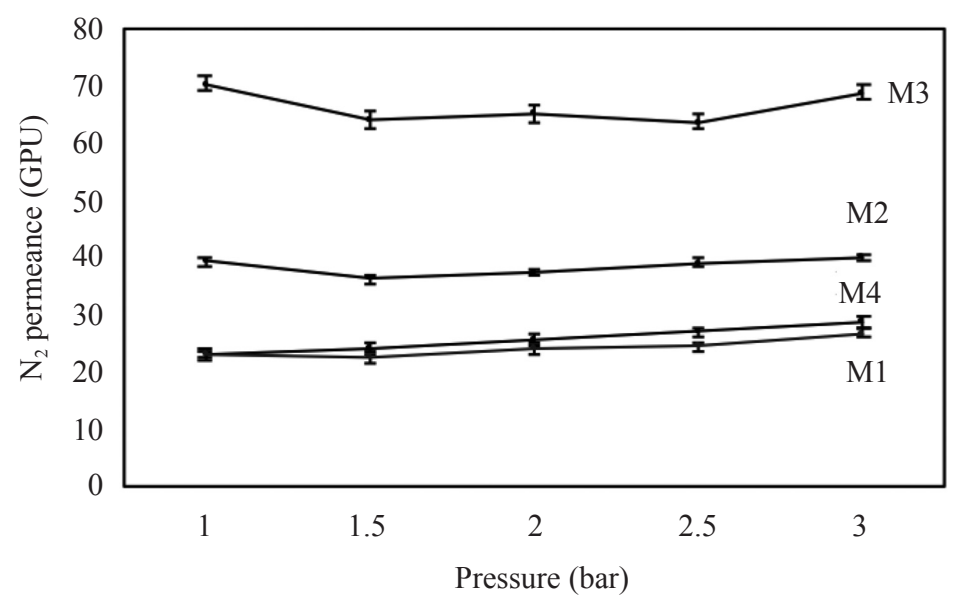

Figure 6: $\mathrm{N}_{2}$ permeance of $\mathrm{CAB}$ membrane fabricated from various ratio of $\mathrm{CAB}$ of Mn 12000 and 70000, M1 (2:1), M2 (1:1), M3 (1:2) and M4 (1:3), with the $250 \mu \mathrm{m}$ casting thickness, $5 \mathrm{~min}$ solvent evaporation time, $4 \mathrm{wt} \%$ polymer concentration and $60 \mathrm{~min} 2$-isopropyl alcohol exchange drying time, followed by $60 \mathrm{~min} n$-hexane drying time.

On the other hand, when the ratio of the Mn of 70000 was increased from 1 (M2) to 2 (M3), the $\mathrm{N}_{2}$ permeance showed a notable increase from $38.36 \pm$ 0.6954 GPU to $66.49 \pm 0.8172$ GPU. The high $\mathrm{N}_{2}$ gas permeance achieved for M3 was due principally to the occurrence of blending of the higher Mn of $\mathrm{CAB}$ at 70000 into the casting solution resulting in the formation of a thinner membrane. This is discussed in Figures 2(b, $d, f$ and $h$ ). These results agreed with Du et al., who stated that the permeance of a membrane is inversely proportional to its cross-sectional thickness. ${ }^{24}$ Therefore, thinner membrane promotes an easier pathway as well as lower resistance for the gases to go through more rapidly. ${ }^{25}$ Thus, when the ratio of the Mn of 70000 increased to 3 (M4), the $\mathrm{N}_{2}$ permeance significantly reduced to $25.70 \pm 0.9598 \mathrm{GPU}$. This was due to the formation of a thicker membrane of $13.39 \pm 0.2098 \mu \mathrm{m}$ (M4) as compared to $9.80 \pm 0.0399 \mu \mathrm{m}(\mathrm{M} 3)$. 


\subsubsection{Separation performance of $\mathrm{CO}_{2} / \mathrm{N}_{2}$}

Figure 7 demonstrates the $\mathrm{CO}_{2} / \mathrm{N}_{2}$ separation performance for the membranes $\mathrm{M} 1$, $\mathrm{M} 2, \mathrm{M} 3$ and M4. According to this figure, the selectivity of $\mathrm{CO}_{2} / \mathrm{N}_{2}$ across the membrane increased from $0.8447 \pm 0.0110$ to $0.9186 \pm 0.0113$ when the ratio of Mn 70000 was increased from 1 (M2) to 2 (M3). The high $\mathrm{CO}_{2} / \mathrm{N}_{2}$ selectivity obtained for M3 was due to the presence of the polar functional group $(-\mathrm{OH})$ at the ratio of 1:2 for Mn 12000 and 70000, respectively. Based on Figure 5, M3 had a higher polar functional group $(-\mathrm{OH})$ compared with $\mathrm{M} 2$. With the presence of this functional group, the $\mathrm{CO}_{2} / \mathrm{N}_{2}$ selectivity was enhanced. Further, Zhang et al. proved that the functional groups demonstrated in the $\mathrm{CAB}$ polymer were highly interactive toward $\mathrm{CO}_{2}$ because it was one of the gas-responsive polymers. ${ }^{26}$

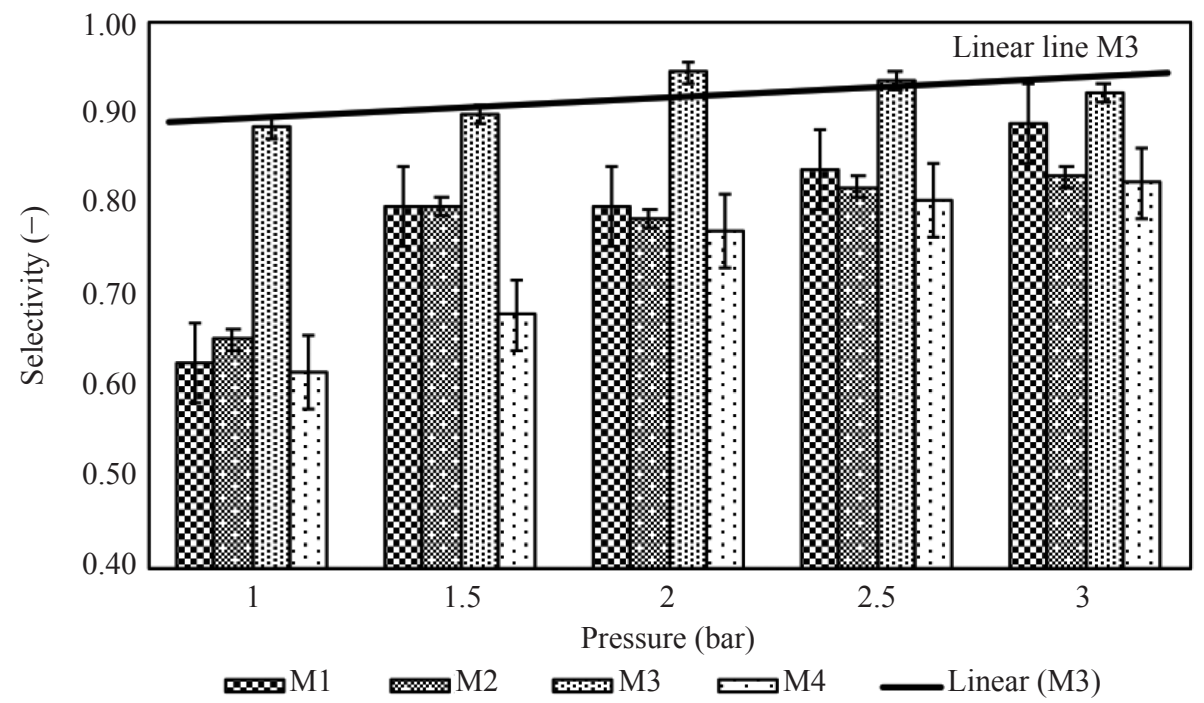

Figure 7: $\mathrm{CO}_{2} / \mathrm{N}_{2}$ selectivity of $\mathrm{CAB}$ membrane fabricated from various ratios of $\mathrm{CAB}$ of Mn 12000 and 70000, M1 (2:1), M2 (1:1), M3 (1:2) and M4 (1:3) with the $250 \mu \mathrm{m}$ casting thickness, $5 \mathrm{~min}$ solvent evaporation time, $4 \mathrm{wt} \%$ polymer concentration and $60 \mathrm{~min}$ 2-isopropyl alcohol exchange drying time, followed by $60 \mathrm{~min} \mathrm{n}$-hexane drying time.

As illustrated in Figure 8, when M3 was prepared with Mn of 12000 and 70000 at a ratio of $1: 2$, it proved in having the best $\mathrm{CO}_{2} / \mathrm{N}_{2}$ selectivity $(0.9186 \pm 0.0113)$ compared with the other membranes (M1, M2 and M4). Figure 5 shows the high $\mathrm{CO}_{2} / \mathrm{N}_{2}$ selectivity attributed to the $\mathrm{Mn}$ of 70000 , which contained a higher $\mathrm{OH}$ group. The $\mathrm{OH}$ group increased the membrane surface hydrophilicity from $69.2^{\circ}$ (M1) to $67.8^{\circ}(\mathrm{M} 3)$ that were more favourable to the non-polar molecules of $\mathrm{CO}_{2}{ }^{27}$ Thus, the permeance of $\mathrm{CO}_{2}$ and the $\mathrm{CO}_{2} / \mathrm{N}_{2}$ selectivity were further enhanced. 


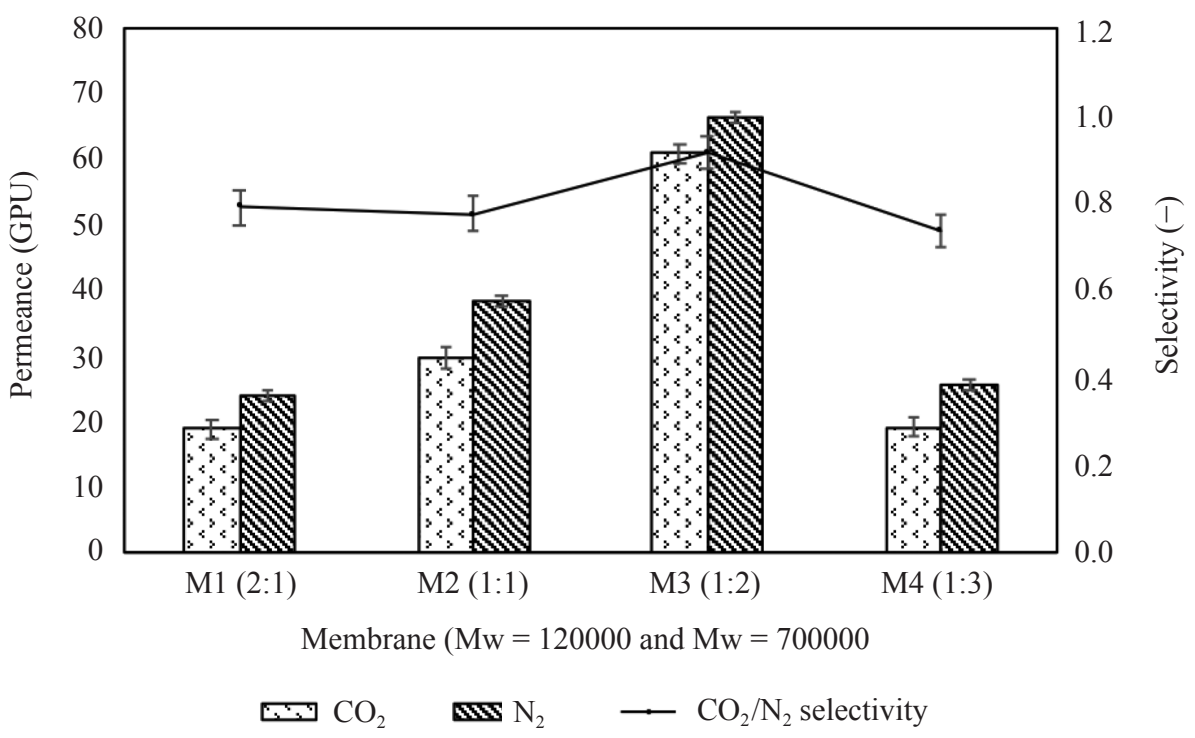

Figure 8: $\quad \mathrm{CO}_{2}$ permeance and $\mathrm{N}_{2}$ permeance (left) and selectivity of $\mathrm{CO}_{2} / \mathrm{N}_{2}$ (right) $\mathrm{CAB}$ membrane fabricated from various ratio of CAB Mn (12000 and 70000) M1 (2:1), M2 (1:1), M3 (1:2) and M4 (1:3) with $250 \mu \mathrm{m}$ casting thickness, $5 \mathrm{~min}$ solvent evaporation time, $4 \mathrm{wt} \%$ polymer concentration and $60 \mathrm{~min}$ 2-isopropyl alcohol exchange drying time, followed by $60 \mathrm{~min} n$-hexane drying time.

\subsection{Effects of CAB of Mn of 30000 Polymer Blends}

In order to enhance the performance of the $\mathrm{CAB}$ membrane, the best membrane (M3) was fabricated at the ratio of 1:2 and the Mn of 12000 and 70000 was further optimised with additional CAB of Mn 30000 at various ratios of 1:2:1 (M5) and 1:2:2 (M6) of Mn 12000, 70000 and 30000, respectively.

\subsubsection{Membrane characterisation}

The surface and cross-sectional morphologies of the cast membranes M5 (1:2:1) and M6 (1:2:2) are demonstrated in Figure 9. According to Figures 9(a, c), a rough surface formed when the ratio of Mn 30000 increased from 1 (M5) to 2 (M6) resulting in the increase of the membrane hydrophilicity when synthesised with Mn of 30000. This is displayed in Figure 10. As seen from this Figure, the contact angle reduced from $80.1^{\circ}$ (M5) to $70.0^{\circ} \pm 0.0200$ (M6). Du et al. proved that as the hydrophilicity of the membrane increased, a rougher membrane surface was formed because of higher surface tension and the ability of forming hydrogen bond with water. As a result, this affected the surface morphology. ${ }^{28}$ 
On the other hand, Figures $9(\mathrm{~b}$ and $\mathrm{d})$ show that the membrane thickness decreased from $9.21 \pm 0.0428 \mu \mathrm{m}$ (M5) to $8.23 \pm 0.0245 \mu \mathrm{m}$ (M6) when the ratio of Mn 30000 increased from 1 (M5) to 2 (M6) in the casting solution. This result was due to the varying diffusion rates between Mn 12000, 70000 and $30000 .^{29}$ The higher ratios of Mn 30000 and 70000 had a relatively lower diffusion rate when compared to the lower ratio of $\mathrm{Mn}$ 12000. Therefore, during immersion in water the lower Mn of 12000 flowed out first due to the higher diffusion rate instead of the higher CAB of Mn 30000 and 70000. ${ }^{13}$ In addition, the higher Mn of 70000 and 30000 had a higher propensity of shrinking when fabricated. ${ }^{12}$ Thus, membrane M6, which was fabricated at a higher concentration of Mn 70000 and 30000 formed a thinner membrane $(8.23 \pm 0.0245 \mu \mathrm{m})$ in comparison to M5 $(9.21 \pm 0.0428 \mu \mathrm{m})$ and M3 $(9.80 \pm 0.0399 \mu \mathrm{m})$.

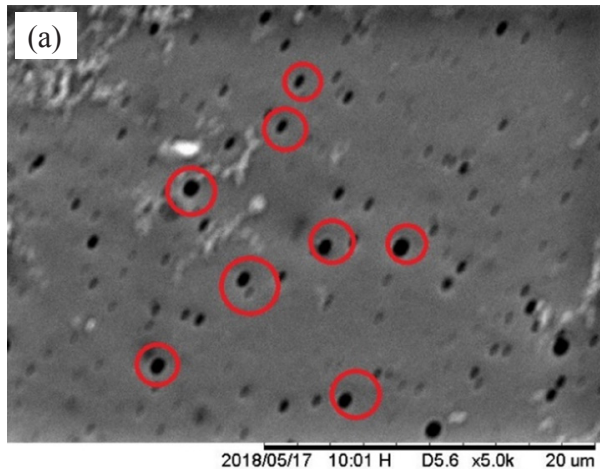

121

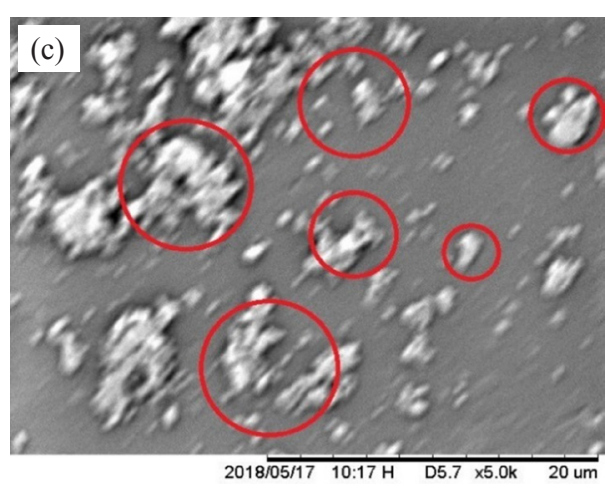

122

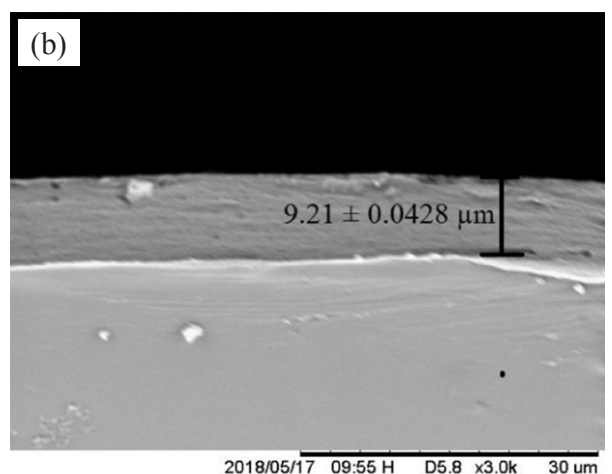

121

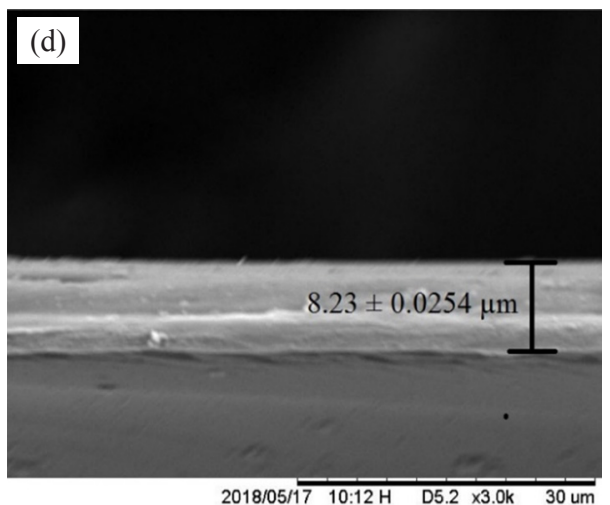

Figure 9: SEM images of $\mathrm{CAB}$ membrane surface and cross sectional structure fabricated from various ratios of CAB Mn (12000, 70000 and 30000), M5 (1:2:1), M6 (1:2:2) with the $250 \mu \mathrm{m}$ casting thickness, $5 \mathrm{~min}$ solvent evaporation time, $4 \mathrm{wt} \%$ polymer concentration and $60 \mathrm{~min} 2$-isopropyl alcohol exchange drying time, followed by 60 min n-hexane drying time. 


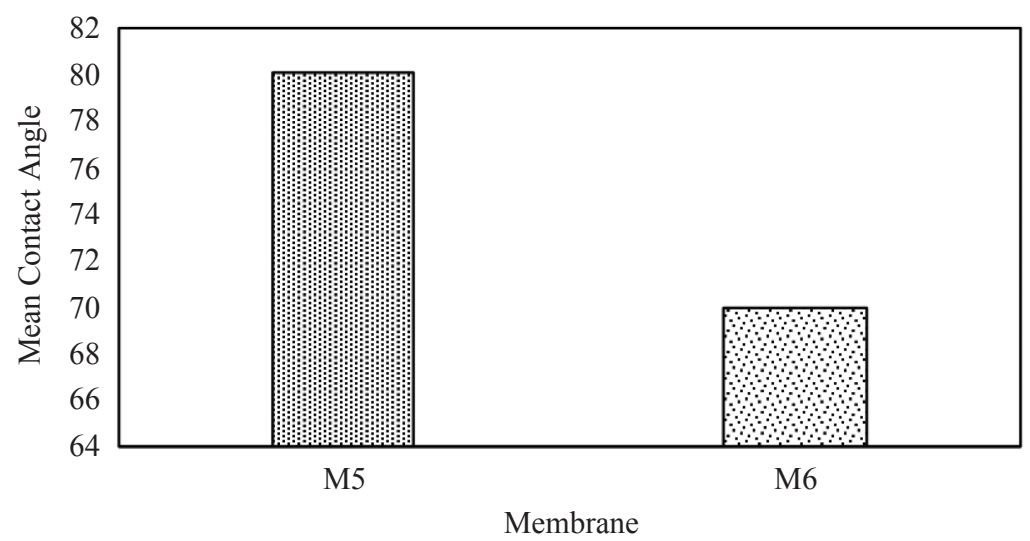

Figure 10: Contact angle of CAB membrane fabricated at Mn of 12000, 70000 and 30000 for (a) 1:2:1 (M5) and (b) 1:2:2 (M6) with the $250 \mu \mathrm{m}$ casting thickness, $5 \mathrm{~min}$ solvent evaporation time, $4 \mathrm{wt} \%$ polymer concentration and $60 \mathrm{~min}$ 2-isopropyl alcohol exchange drying time, followed by 60 min n-hexane drying time.

\subsubsection{Separation performance of the membrane}

\subsubsection{Single gas permeation test of $\mathrm{CO}_{2}$}

The results obtained from the single gas permeance test of $\mathrm{CO}_{2}$ for M5 (1:2:1) and M6 (1:2:2) were then compared with M3. This is demonstrated in Figure 11. Based on this figure, the $\mathrm{CO}_{2}$ permeance increased with the addition of $\mathrm{Mn} 30000$ into the polymer matrix of M3. Figure 11 also shows that the highest $\mathrm{CO}_{2}$ permeance was $262.58 \pm 1.2138 \mathrm{GPU}$ for M6 (1:2:2), which was 5 times higher than the $\mathrm{CO}_{2}$ permeance of M3 $(61.04 \pm 1.0288 \mathrm{GPU})$. The increase was due to reduction in the membrane thickness from $9.80 \pm 0.0399 \mu \mathrm{m}(\mathrm{M} 3$, Figure 2(d)) to $8.23 \pm 0.0254$ $\mu \mathrm{m}$ (M6, Figure 9(f)) when the ratio of Mn 30000 increased to 2 (M6). Further, when the ratio of Mn 30000 increased from 0 (M3) to 2 (M6), the stretching of the polar groups $(-\mathrm{OH})$ increased, as presented in the ATR-FTIR spectroscopy (Figure 12). Hence, the $\mathrm{CO}_{2}$ permeance increased because of the high interaction between the polar group $(-\mathrm{OH})$ and the non-polar $\mathrm{CO}_{2}$. 


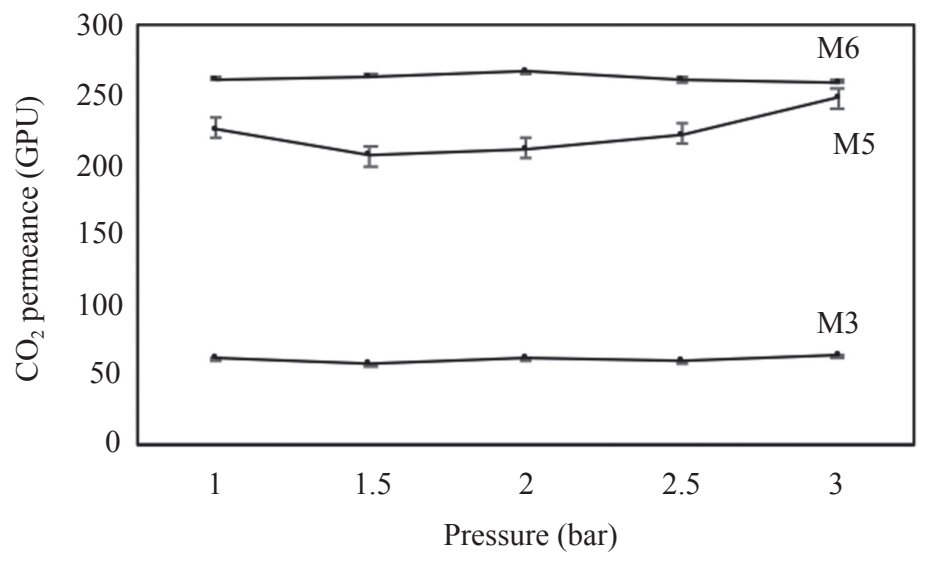

Figure 11: $\mathrm{CO}_{2}$ permeance of CAB membrane fabricated at Mn of 12000, 70000 and 30000, 1:2:1 (M5), 1:2:2 (M6) and M3 (1:2) with the $250 \mu \mathrm{m}$ casting thickness, $5 \mathrm{~min}$ solvent evaporation time, $4 \mathrm{wt} \%$ polymer concentration and $60 \mathrm{~min}$ 2-isopropyl alcohol exchange drying time, followed by 60 min n-hexane drying time.

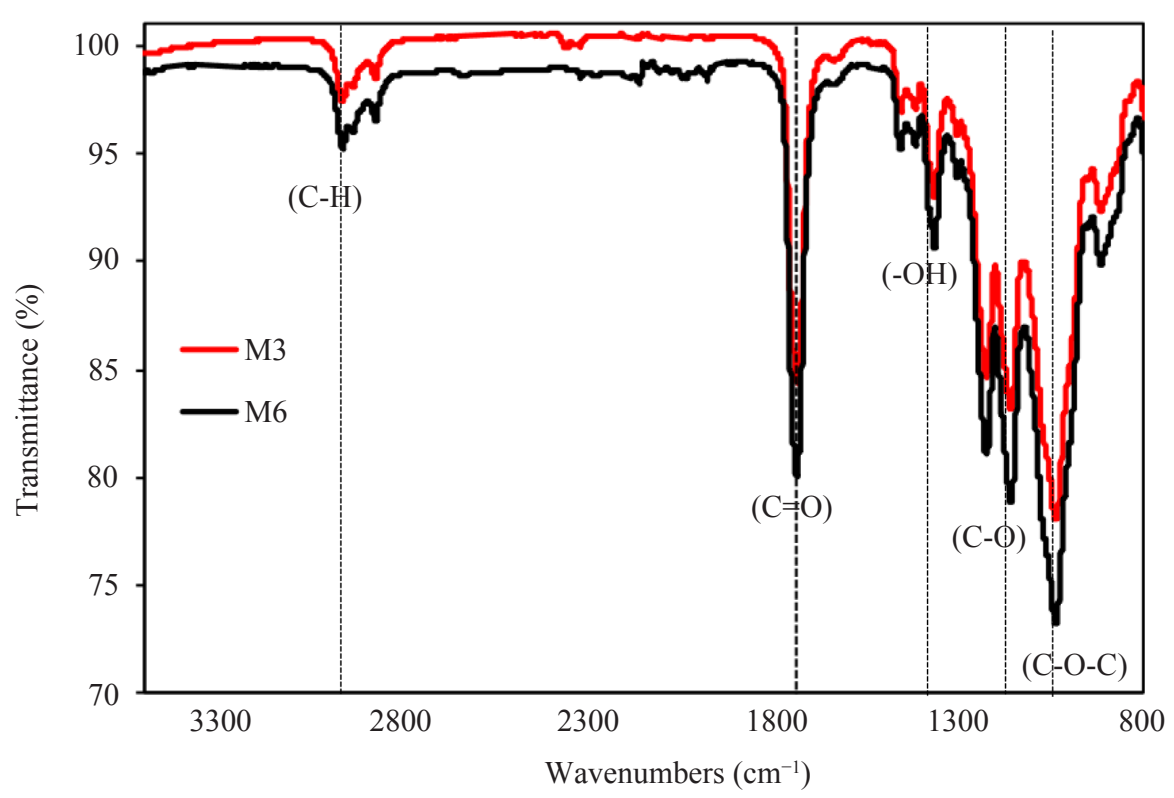

Figure 12: ATR-FTIR spectra of CAB membrane fabricated at Mn of 12000, 70000 and 30000, 1:2:2 (M6) and M3 (1:2), with the $250 \mu \mathrm{m}$ casting thickness, $5 \mathrm{~min}$ solvent evaporation time, $4 \mathrm{wt} \%$ polymer concentration and $60 \mathrm{~min} 2$-isopropyl alcohol exchanges drying time, followed by $60 \mathrm{~min}$-hexane drying time. 


\subsubsection{Single gas permeation test of $N_{2}$}

As displayed in Figure 13, the N2 permeance increased from $66.49 \pm 1.3390 \mathrm{GPU}$ to $178.25 \pm 3.6033 \mathrm{GPU}$ when the ratio of Mn 30000 increased from 0 (M3) to 1 (M5). This was due to the formation of a thinner membrane that resulted in lower resistance to gas permeation. On the contrary, when the ratio of Mn 30000 was increased to 2 (M6) the $\mathrm{N}_{2}$ permeance showed gradual reduction to $138.36 \pm$ 1.5479 GPU. This is presented in Figure 13. In addition, this reduction might be attributed to the increase in the carbonyl $(\mathrm{C}=\mathrm{O})$ groups as demonstrated in Figure 14, that are competent to interact with the $\mathrm{N}_{2}$ molecules by its $\pi$-electron system. ${ }^{16}$ Thus, this strengthened the intermolecular interactive force between $\mathrm{N}_{2}$ molecules and $\mathrm{C}=\mathrm{O}$ group that indicate a greater mass transfer resistant that reduced the $\mathrm{N}_{2}$ gas permeance through the membrane. ${ }^{16}$

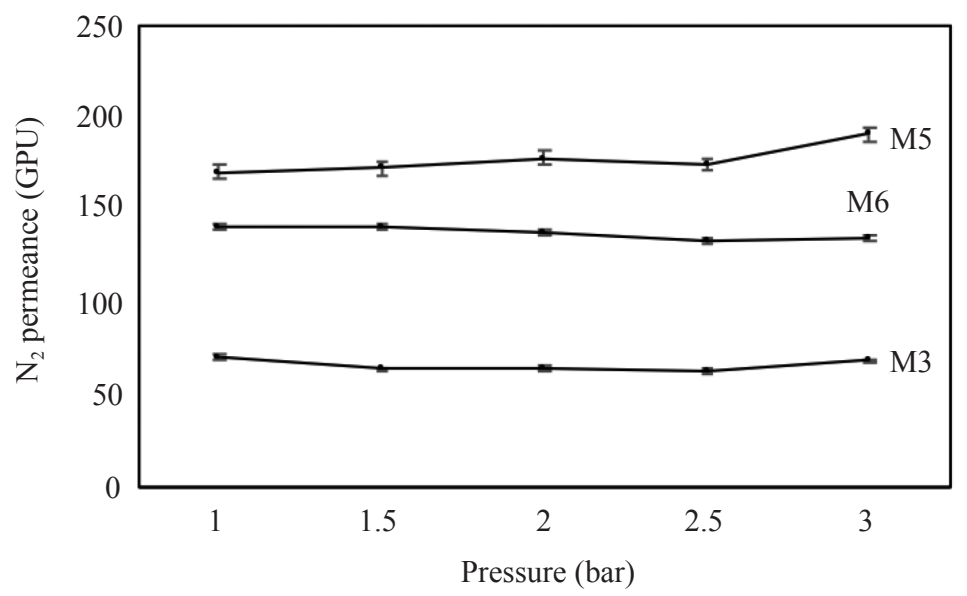

Figure 13: $\mathrm{N}_{2}$ permeance of CAB membrane fabricated at $\mathrm{Mn}$ of 12000,70000 and 30000, 1:2:1 (M5), 1:2:2 (M6) and M3 (1:2), with the $250 \mu \mathrm{m}$ casting thickness, $5 \mathrm{~min}$ solvent evaporation time, $4 \mathrm{wt} \%$ polymer concentration and $60 \mathrm{~min}$ 2-isopropyl alcohol exchange drying time, followed by 60 min n-hexane drying time. 


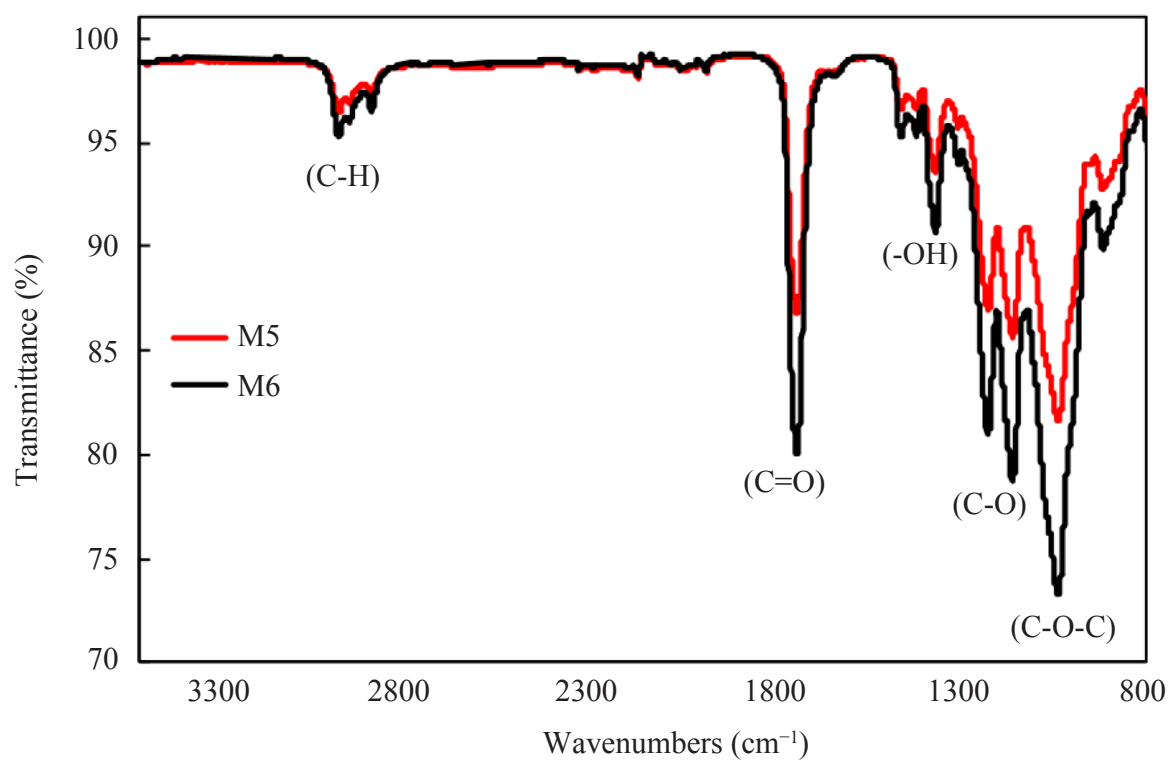

Figure 14: ATR-FTIR spectra of CAB membrane fabricated at Mn of 12000, 70000 and $30000,1: 2: 1$ (M5) and 1:2:2 (M6), with the $250 \mu \mathrm{m}$ casting thickness, 5 min solvent evaporation time, $4 \mathrm{wt} \%$ polymer concentration and $60 \mathrm{~min} 2$-isopropyl alcohol exchanges drying time, followed by $60 \mathrm{~min} n$-hexane drying time.

\subsubsection{Separation performance of $\mathrm{CO}_{2} / \mathrm{N}_{2}$}

The optimisation of the blended ratios of $\mathrm{CAB}$ of $\mathrm{Mn} 30000$ into the best membrane that was obtained upon the optimisation of CAB of Mn 12000 and 70000 proved that the separation performance successfully improved. The $\mathrm{CO}_{2}$ permeance of the membrane upon increasing the Mn of CAB to 30000 in the polymer blend, dramatically increased from $61.04 \pm 1.0288 \mathrm{GPU}$ (M3) to 262.58 \pm 1.2138 GPU (M6). As exhibited in Figure 15, this resulted in the enhancement of $\mathrm{CO}_{2} / \mathrm{N}_{2}$ selectivity from $0.9186 \pm 0.0113(\mathrm{M} 3)$ to $1.8986 \pm 0.0195$ (M6). This was due to the increase in the surface hydrophilicity of M6 that attracted the non-polar molecules of $\mathrm{CO}_{2}$, as proven by the contact angle results (Figure 10), which reduced from $80.1^{\circ}$ (M5) to $70.0^{\circ} \pm 0.0200$ (M6). In addition, the $\mathrm{CO}_{2} / \mathrm{N}_{2}$ selectivity further improved when the ratio of Mn 30000 increased from 0 (M3) to 2 (M6) thereby, increasing the polar functional group (-OH) of the membrane (Figure 12). Eventually, the attraction between $\mathrm{CO}_{2}$ and the membrane improved.

Noticeably, the blending of Mn 30000 within CAB membrane structure had improved the $\mathrm{CO}_{2}$ permeance of the present work as compared to other research works with the same casting conditions (Table 2). According to this table, the 
membrane fabricated with $\mathrm{CAB}$ of $\mathrm{Mn} 30000$ at ratio of 2 showed the highest permeance of $\mathrm{CO}_{2}$. This might be due to the enhanced surface hydrophilicity that attracted non-polar molecules $\mathrm{CO}_{2}$, as discussed previously in Figure 10.

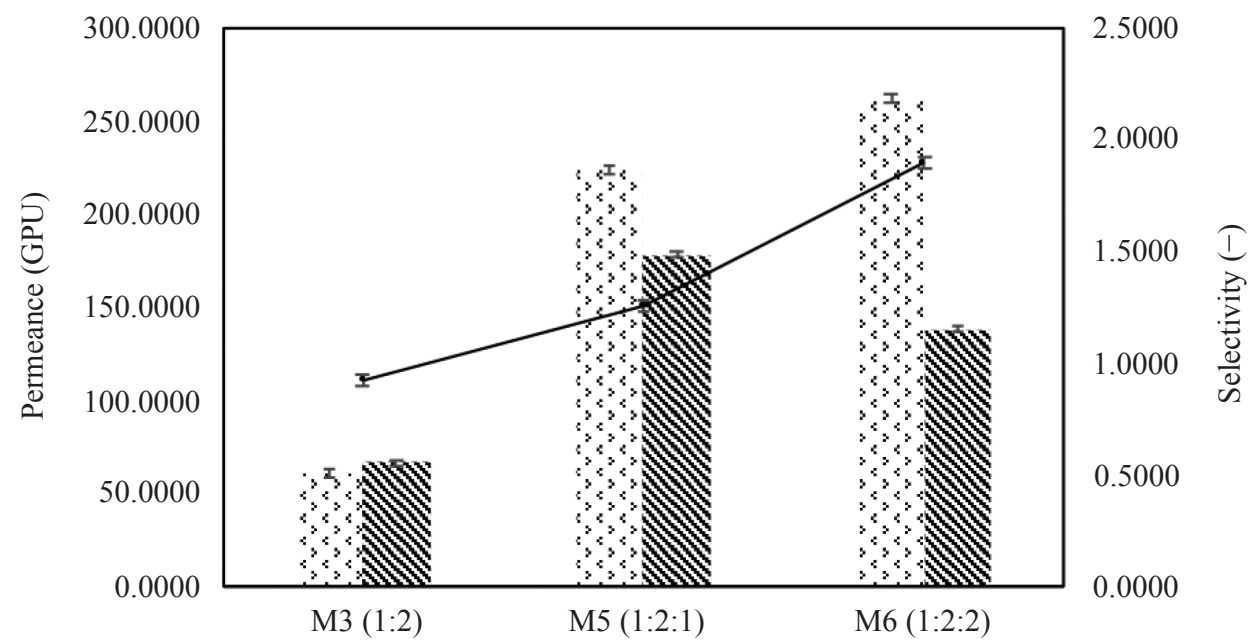

Membrane CAB of Mn (120000; 70000; 12000)

$\because \mathrm{CO}_{2} \quad \mathrm{~N} \mathrm{~N}_{2} \longrightarrow \mathrm{CO}_{2} / \mathrm{N}_{2}$ selectivity

Figure 15: $\mathrm{CO}_{2}$ permeance and $\mathrm{N}_{2}$ permeance (left) and selectivity of $\mathrm{CO}_{2} / \mathrm{N}_{2}$ (right) of $\mathrm{CAB}$ membrane fabricated at $\mathrm{Mn}$ of 12000, 70000 and 30000 1:2:1 (M5), 1:2:2 (M6) and M3 (1:2), with the $250 \mu \mathrm{m}$ casting thickness, 5 min solvent evaporation time, $4 \mathrm{wt} \%$ polymer concentration and $60 \mathrm{~min} 2$-isopropyl alcohol exchange drying time, followed by $60 \mathrm{~min} n$-hexane drying time.

Table 2: A comparison between current study gas separation performance results and other literature works.

\begin{tabular}{|c|c|c|c|c|c|c|c|}
\hline \multirow{2}{*}{ References } & \multicolumn{4}{|c|}{ CAB (wt\%) (Mn) } & \multicolumn{2}{|c|}{ Permeability (GPU) } & \multirow{2}{*}{$\begin{array}{c}\text { Selectivity } \\
\mathrm{CO}_{2} / \mathrm{N}_{2}\end{array}$} \\
\hline & 12000 & 70000 & 65000 & 30000 & $\mathrm{CO}_{2}$ & $\mathrm{~N}_{2}$ & \\
\hline \multirow[t]{3}{*}{ Present work } & 1 & 2 & 0 & 0 & $\begin{array}{c}61.04 \\
(-76.75 \%)\end{array}$ & $\begin{array}{c}66.49 \\
(-51.95 \%)\end{array}$ & $\begin{array}{c}0.7396 \\
(-51.62 \%)\end{array}$ \\
\hline & 1 & 2 & 0 & 1 & $\begin{array}{c}223.38 \\
(265.95 \%)\end{array}$ & $\begin{array}{c}178.25 \\
(168.09 \%)\end{array}$ & $\begin{array}{c}1.2529 \\
(36.39 \%)\end{array}$ \\
\hline & 1 & 2 & 0 & 2 & $\begin{array}{c}262.58 \\
(330.16 \%)\end{array}$ & $\begin{array}{c}138.36 \\
(108.10 \%)\end{array}$ & $\begin{array}{c}1.8986 \\
(106.68 \%)\end{array}$ \\
\hline Cha et al. ${ }^{16}$ & 1 & 0 & 1 & 0 & 106.87 & 15.31 & 6.982 \\
\hline Lee et al. ${ }^{19}$ & 1 & 1 & 1 & 0 & 205.09 & 249.34 & 0.84 \\
\hline Lee et al. ${ }^{30}$ & 0 & 1 & 0 & 0 & 40.51 & 119.20 & 2.94 \\
\hline
\end{tabular}




\section{CONCLUSION}

In this study, the $\mathrm{CAB}$ membranes with different molecular weights $(\mathrm{Mn})$ were successfully fabricated by optimising the $\mathrm{CAB}$ polymer blends with $\mathrm{Mn}$ of 12000,70000 and 30000 . The results showed that the Mn of CAB significantly affected the $\mathrm{CO}_{2} / \mathrm{N}_{2}$ selectivity of the membrane. When the $\mathrm{CAB}$ blend ratio of Mn 70000:12000 increased from 2:1 (M1) to 1:2 (M3), the $\mathrm{CO}_{2} / \mathrm{N}_{2}$ selectivity enhanced from $0.7396 \pm 0.0396$ (M1) to $0.9186 \pm 0.0113$ (M3) due to the presence of the higher hydroxyl group $(-\mathrm{OH})$ that attracted the non-polar $\mathrm{CO}_{2}$. However, on further increasing the ratio to 1:3 (M4) the separation performance showed insignificant changes due to long plugging effect by the long chain polymer. To enhance the separation performance, M3 (1:2) was optimised by adding CAB of Mn 30000 into the polymer blend. When $\mathrm{CAB}$ of $\mathrm{Mn} 30000$ was increased from the ratio of 0 (M3) to 2 (M6), the $\mathrm{CO}_{2} / \mathrm{N}_{2}$ selectivity increased significantly from $0.9186 \pm 0.0113(\mathrm{M} 3)$ to $1.8986 \pm 0.0195$ (M6), resulting in a higher $\mathrm{CO}_{2}$ permeance of $262.58 \pm 1.2138 \mathrm{GPU}$ as compared to $61.04 \pm 1.0288 \mathrm{GPU}$ (M3). This was mainly due to the thinner membrane fabricated for M6 (8.23 \pm $0.0245 \mu \mathrm{m})$ and $\mathrm{M} 3(9.80 \pm 0.0399 \mu \mathrm{m})$. In summary, different molecular weights of $\mathrm{CAB}$ influences the $\mathrm{CO}_{2} / \mathrm{N}_{2}$ selectivity and permeance of the membrane significantly.

\section{REFERENCES}

1. Weissburg, M. \& Draper, A. M. (2019). Impacts of global warming and elevated $\mathrm{CO}_{2}$ on sensory behavior in predator-prey interactions: A review and synthesis. Front. Ecol. Environ., 7, 72. https://doi.org/10.3389/fevo.2019.00072

2. Buhre, B. J. et al. (2005). Oxy-fuel combustion technology for coal-fired power generation. Prog. Energy Combust. Sci., 31(4), 283-307. https://doi.org/10.1016/j. pecs.2005.07.001

3. Stolaroff, J. K. et al. (2018). Author correction: Energy use and life cycle greenhouse gas emissions of drones for commercial package delivery. Nat. Comm., 9(1), 1054. https://doi.org/10.1038/s41467-018-03457-9

4. Abedini, R. \& Mosayebi, A. (2011). Investigation of membrane technology in gas separation process. Adv. Sust. Petr. Eng. Sci., 3(3), 211-211. https://10.1016/ j.jngse.2017.01.023

5. Strathmann, H., Giorno, L. \& Drioli, E. (2011). Introduction to membrane science and technology. Weinheim: Wiley-VCH.

6. Xie, S.-M. et al. (2008). Chiral separation of (R, S)-2-phenyl-1-propanol through cellulose acetate butyrate membranes. J. Membr. Sci., 321(2), 293-298. https://doi.org/10.1016/j.tetasy.2009.03.032 
7. Asgarkhani, M. A. H., Mousavi, S. M. \& Saljoughi, E. (2013). Cellulose acetate butyrate membrane containing titanium dioxide nanoparticle: Preparation, characterization and permeation study. Korean J. Chem. Eng., 30(9), 1819-1824, https://doi.org/10.1007/s11814-013-0122-8

8. Hashino, M. et al. (2011). Effects of three natural organic matter types on cellulose acetate butyrate microfiltration membrane fouling. J. Membr. Sci., 379(1), 233-238. https://doi.org/10.1016/j.memsci.2011.05.068

9. Shanbhag, A. et al. (2007). Application of cellulose acetate butyrate-based membrane for osmotic drug delivery. Cell., 14(1), 65-71. https://doi.org/10.1007/ s10570-006-9091-y

10. Wessling, M., Lidon Lopez, M. \& Strathmann, H. (2001). Accelerated plasticization of thin-film composite membranes used in gas separation. Sep. Purif. Technol., 24(1), 223-233. https://doi.org/10.1016/S1383-5866(01)00127-7

11. Chakrabarty, B., Ghoshal, A. K. \& Purkait, M. K. (2008). Effect of molecular weight of PEG on membrane morphology and transport properties. J. Membr. Sci., 309(1), 209-221. https://doi.org/10.1016/j.memsci.2007.10.027

12. Kee, C. M. \& Idris, A. (2010). Permeability performance of different molecular weight cellulose acetate hemodialysis membrane. Sep. Purif. Technol., 75(2), 102-113. https://doi.org/10.1016/j.seppur.2010.08.013

13. Chuang, W.-Y. et al. (2000). The effect of polymeric additives on the structure and permeability of poly (vinyl alcohol) asymmetric membranes. Polym., 41(15), 5633-5641. https://doi.org/10.1016/S0032-3861(99)00818-6

14. Yu, L., Dean, K. \& Li, L. (2006). Polymer blends and composites from renewable resources. Prog. Polym. Sci., 31(6), 576-602. https://doi.org/10.1016/ j.progpolymsci.2006.03.002

15. Lee, R. J. et al. (2019). Rheological evaluation of the fabrication parameters of cellulose acetate butyrate membrane on the $\mathrm{CO}_{2} / \mathrm{N}_{2}$ seperation performance. Boca Raton: CRC Press.

16. Cha, W. C. \& Jawad, Z. A. (2019). The influence of cellulose acetate butyrate membrane structure on $\mathrm{CO} 2 / \mathrm{N} 2$ separation: Effect of casting thickness and solvent exchange time. Chem. Eng. Comm., 1-19. https://doi.org/10.1080/00986445.2019 .1605359

17. Jawad, Z. et al. (2015). Incorporation of inorganic carbon nanotubes fillers into the CA polymeric matrix for improvement in $\mathrm{CO}_{2} / \mathrm{N}_{2}$ separation. Curr. Nanosci., 11(1), 69-79. https://10.2174/1573413710666140922224633

18. Sugu, L. \& Jawad, Z. A. (2019). Formation of low acetyl content cellulose acetate membrane for $\mathrm{CO}_{2} / \mathrm{N}_{2}$ separation. J. Phys. Sci., 30(1). https://doi.org/10.21315/ jps2019.30.1.9

19. Lee, S. T., Pang, J. N. \& Jawad, Z. A. (2019). Functionalised multi-walled carbon nanotubes/cellulose acetate butyrate mixed matrix membrane for $\mathrm{CO}_{2} / \mathrm{N}_{2}$ separation. J. Phys. Sci., 30(2), 99-135. https://doi.org/10.21315/jps2019.30.2

20. Ahmad, A., Jawad, Z., Low, S. \& Zein, S. (2014). A cellulose acetate and multi-walled carbon nanotube mixed matrix membrane for carbon dioxide and nitrogen separation. J. Membr. Sci., 451, 55-66. https://doi.org/10.1016/j. memsci.2013.09.043 
21. Ismail, A. F. et al. (2011). Gas separation performance of polyethersulfone and multi-walled carbon nanotubes mixed matrix membranes. Sep. Purif. Technol., 80(1), 20-31. https://doi.org/10.1016/j.seppur.2011.03.031

22. Kanis, L. A. et al. (2014). Cellulose acetate butyrate/poly (caprolactonetriol) blends: Miscibility, mechanical properties, and in vivo inflammatory response. J. Biomater. Appl., 29(5), 654-661. https://doi.org/10.1177/0885328214542488

23. Shan, $M$. et al. (2012). Influence of chemical functionalization on the $\mathrm{CO}_{2} / \mathrm{N}_{2}$ separation performance of porous graphene membranes. Nanosc., 4(17), 5477-5482. https://doi.org/10.1039/c2nr31402a

24. Du, N. et al. (2012). Advances in high permeability polymeric membrane materials for $\mathrm{CO}_{2}$ separations. Energy Environ. Sci., 5(6), 7306-7322. https://doi.org/10.1039/c1ee02668b

25. Li, H. et al. (2013). Ultrathin, molecular-sieving graphene oxide membranes for selective hydrogen separation. Sci., 342(6154), 95-98. https://10.1126/science .1236686

26. Zhang, Q., Lei, L. \& Zhu, S. (2017). Gas-responsive polymers. ACS Macro Lett., 6, 515-522. https://doi.org/10.1021/acsmacrolett.7b00245

27. Liu, L., Chakma, A. \& Feng, X. (2004). Preparation of hollow fiber poly (ether block amide)/polysulfone composite membranes for separation of carbon dioxide from nitrogen. Chem. Eng. J., 105(1-2), 43-51. https://doi.org/10.1016/j.cej.2004 .08 .005

28. Du, J. R., Peldszus, S., Huck, P. M. \& Feng, X. (2009). Modification of poly (vinylidene fluoride) ultrafiltration membranes with poly (vinyl alcohol) for fouling control in drinking water treatment. Water Res., 43(18), 4559-4568. https://doi.org/10.1016/j.watres.2009.08.008

29. Idris, A. \& Yet, L. K. (2006). The effect of different molecular weight PEG additives on cellulose acetate asymmetric dialysis membrane performance. J. Membr. Sci., 280(1-2), 920-927, https://doi.org/10.1016/j.memsci.2006.03.010.

30. Lee, R., Jawad, Z., Ahmad, A. \& Chua, H. (2018). Incorporation of functionalized multi-walled carbon nanotubes (MWCNTs) into cellulose acetate butyrate (CAB) polymeric matrix to improve the $\mathrm{CO}_{2} / \mathrm{N}_{2}$ separation. Proc. Safety Environ. Prot., 117, 159-167. https://doi.org/10.1016/j.psep.2018.04.021 